\title{
O uso de tinta veneno em embarcações de pesca e turismo: efeitos da poluição por microplástico nas águas marítimas da Baixada Santista
}

\section{The use of poison ink in fishing and tourism boats: effects of microplastic pollution in the maritime waters of Baixada Santista}

DOI: $10.46814 / \operatorname{lajdv3n1-043}$

Recebimento dos originais: 30/10/2020

Aceitação para publicação: 23/12/2020

\author{
Fagner Evangelista Severo \\ Mestre em Ecologia pela Universidade Santa Cecília \\ Instituição: Universidade Santa Cecília \\ Endereço: Rua Oswaldo Cruz, 277 - Boqueirão, Santos - SP, 11045-907 \\ E-mail: fagner.sev@ig.com.br
}

Maria Cristina Pereira Matos

Pós-doutorada pelo Programa de Pós-Graduação em Administração da Universidade de São Paulo (FEA-USP)

Instituição: Universidade Santa Cecília

Endereço: Rua Oswaldo Cruz, 277 - Boqueirão, Santos - SP, 11045-907

E-mail: cris_matos@uol.com.br

\section{RESUMO}

Este estudo realizou um levantamento da problemática da poluição por microplásticos e compostos organoestânicos, como o Tributilestanho (TBT) ou Trifenilestanho (TPhT) presentes nas tintas utilizadas nas embarcações de madeira. Para identificar a presença de tais poluentes este estudo empregou a metodologia de caráter exploratório, de cunho qualitativo, através de pesquisa de campo junto aos pescadores e donos de embarcações de pesca na Vila da Barra do Una, Peruíbe, SP, no entreposto de pesca de Santos, SP e de embarcações de passeio no píer do Saldanha da Gama, também em Santos, SP. Os resultados obtidos permitiram observar que são utilizadas tintas venenosas para coibir a ação de microorganismos incrustantes que se fixam aos cascos das embarcações e resultam em problemas para os usuários e para a vida marinha. Além disso, identificou-se que no processo de raspagem dos barcos para procedimentos de novas pinturas, partículas de plástico derivadas das tintas removidas são descartadas no mar, favorecendo a contaminação das áreas. A constatação de que esses tipos de embarcações marítimas são todas cobertas por tintas venenosas que deixam resíduos de plástico tóxico no ambiente, indicam a necessidade de novas pesquisas que visem desenvolver tintas anti-incrustantes para os cascos de embarcações que não contribuam para a poluição marinha.

Palavras-chave: Navegação marítima, Tinta anti-incrustante, Microplático, Microlixo, Baixada Santista.

\begin{abstract}
This study carried out a survey of the problem of microplastic pollution and organotin compounds, such as Tributyltin (TBT) or Triphenyltin (TPhT), present in the paints used on wooden boats. To identify the presence of such pollutants this study used an exploratory methodology, of qualitative nature, through field research with fishermen and fishing boat owners in the Barra do Una Village, Peruíbe, SP, in the Santos fishing harbor, SP, and in the Saldanha da Gama pier, also in Santos, SP. The results obtained allowed us to observe that poisonous paints are used to curb the action of fouling
\end{abstract}


microorganisms that attach to the hulls of the boats and result in problems for the users and for marine life. Besides this, it was identified that in the process of scraping the boats for new painting procedures, plastic particles derived from the removed paints are discarded in the sea, favoring the contamination of the areas. The finding that these types of maritime vessels are all covered with poisonous paints that leave toxic plastic residues in the environment, indicate the need for further research aimed at developing anti-fouling paints for the hulls of vessels that do not contribute to marine pollution.

Keywords: Marine navigation, Antifouling paint, Microplastic, Microlixo, Baixada Santista.

\section{INTRODUÇÃO}

A busca constante do ser humano por métodos que possam facilitar a sua vida, enquanto espécie, sempre foi um desafio. Ao longo das eras e com os avanços na área do conhecimento, muitas estratégias foram empregadas, objetivando o alcance de metas que pudessem facilitar as atividades do cotidiano das pessoas.

Nesse contexto, aspectos relacionados ao desenvolvimento social, cultural e econômico foram sendo agregados, ao mesmo tempo em que começaram a surgir graves problemas ambientais, relacionados principalmente à poluição e ao descarte dos diferentes tipos de lixo no mar.

Atualmente, os níveis de poluição marinha e costeira devidos à deposição de resíduos sólidos são questões debatidas com relevância pela comunidade científica [1].

Diante da relevância da abordagem da temática ora proposta sobre a poluição marinha, duas vertentes relacionadas aos problemas ambientais nos mares foram eleitas para contextualizar o presente estudo: a contaminação das águas pelas tintas anti-incrustantes e os microcroplásticos.

Assim, se faz necessário esclarecer que os grânulos de plásticos que constituem a forma principal com que as resinas plásticas são produzidas e comercializadas, são chamados de pellets e servem de matéria prima nas indústrias de transformação, originando os mais variados objetos, que são produzidos após o seu derretimento e moldagem do produto final [2].

Os microplásticos, materiais derivados do petróleo e que possuem particularidades em relação ao aspecto e tamanho, constantemente contribuem para a poluição dos mares, haja vista que podem ser facilmente conduzidos pelo vento, águas ou mesmo derramados em oportunidade das movimentações e resultam em grandes quantidades de micro partículas espalhadas pelos mares.

Por outro lado e numa vertente tão poluidora quanto aquela deixada pelos microplásticos, estão também as tintas anti-incrustantes, utilizadas na pintura externa das embarcações, visando minimizar o ataque constante de microorganismos marinhos. Estes se acoplam aos cascos das embarcações, e causam efeitos que podem ir desde a morosidade nas movimentações, até mesmo chegar ao ponto de 
inutilização das mesmas. Dentre os principais componentes químicos utilizados nessas tintas, encontram-se, compostos orgânoestânicos como o Tributilestanho (TBT) ou Trifenilestanho (TPhT).

O composto está entre os mais tóxicos já introduzidos propositalmente no ambiente aquático. Um dos principais efeitos do uso de tais substâncias é o envenenamento do sistema biológico, principalmente de moluscos e ostras, originando mutações e condenando espécies à extinção. Destacase que entre os efeitos mais significativos, estão os do TBT sobre a reprodução de ostras e neogastrópodes [3].

O problema chamou a atenção do Comitê de Proteção do Ambiente Marinho (MEPC) da Organização Marítima Internacional (IMO), interessada na segurança da navegação e prevenção da poluição marinha [4].

Em 2001, por intermédio da Convenção Internacional sobre Controle de Sistemas Antifouling Danosos em Navios, a IMO (Organização Marítima Internacional) aprovou o banimento global do uso do TBT e de outros compostos organoestânicos na composição de tintas antifouling. A aplicação desta medida estava prevista para janeiro de 2003, porém só passou a vigorar em setembro de 2008, acarretando assim, atraso sobre a previsão inicial [5].

Considerando os sérios problemas ambientais decorrentes do contato direto dos materiais derivados de plásticos e seus componentes químicos nas águas brasileiras e internacionais, este estudo objetivou realizar um levantamento da problemática da poluição marinha por microplásticos, incluindo as tintas marítimas anti-incrustantes como vetor de contaminação na região da Baixada Santista, SP.

\section{MATERIAIS E MÉTODOS}

O presente trabalho adotou uma metodologia exploratória, de caráter qualitativo, empregandose como método, além da pesquisa bibliográfica, uma pesquisa de campo, aplicando a técnica do questionário semi-estruturado, direcionada aos donos de embarcações marítimas de madeira. A área de estudo se deu em três localidades na Baixada Santista no período de 5 a 15 de setembro de 2015: Barra do Una, Peruíbe, SP; Entreposto de Pesca da cidade de Santos, Santos, SP e Píer do Clube de Regatas Saldanha da Gama, Santos, SP. Tais locais foram eleitos por concentrarem embarcações de madeira, facilitando assim, a verificação do uso de tintas anti-incrustantes. Além destas localidades, foi realizada visita a uma das lojas de tintas para embarcações na cidade de Santos, para identificar os tipos de produtos mais comercializados, seus componentes principais e seus valores de mercado.

Os respondentes da pesquisa de campo foram os pescadores e donos das embarcações de pesca artesanal na Barra do Una, Peruíbe, SP, os pescadores comerciais de embarcações que desembarcam no entreposto de pesca da cidade de Santos, SP e os marinheiros de embarcações turísticas do Píer do Saldanha da Gama, também em Santos. 
O questionário foi organizado com perguntas relativas ao perfil do entrevistado; tipos das embarcações; tintas utilizadas nas pinturas; conhecimento do entrevistado sobre as tintas veneno, efeitos dos compostos orgânoestânicos na natureza e embalagens, e locais para aquisição de tais produtos.

\section{RESULTADOS E DISCUSSÃO}

Os resultados mostram que todos os entrevistados utilizam as tintas anti-incrustantes venenosas nas suas embarcações. As marcas, nem sempre foram lembradas, todavia, os entrevistados foram unânimes afirmando utilizar a tinta veneno nos cascos para proteger contra a ação dos animais incrustantes que prejudicam a madeira.

É interessante destacar que os entrevistados salientaram os custos com a parada da embarcação para raspagem e novas pinturas. Foram apontadas como ações realizadas em curtos períodos de tempo (a cada seis meses), sendo necessário realizar manobras de puxada da embarcação para estaleiros para submeter o barco à raspagens e novas pinturas.

Os pescadores da Barra do Una inclusive destacaram que, em razão da localização destes, as manobras de puxada tornam-se morosas porque precisam ir até os estaleiros de outra cidade, em Peruíbe, $25 \mathrm{KM}$ de distância, ao mesmo tempo em que tais procedimentos demonstram-se caros, porque são obrigados a custear o aluguel diário do estaleiro. Em razão disto, algumas vezes as embarcações são encalhadas na maré baixa em barrancos de terra no próprio rio Una, onde são realizadas as raspagens dos microorganismos grudados e novas pinturas são realizadas, resultando no despejo de microplásticos no leito do rio, que consequentemente são levados pelas águas.

Os respondentes indicaram lojas de tintas náuticas em Santos e Peruíbe, como sendo as localidades mais fáceis para aquisição de materiais com essas qualificações. Na visita feita a uma destas lojas, na região do Entreposto de Pesca em Santos, foi constatado que o preço médio de um galão de tinta de $3.600 \mathrm{ml}$ varia de preços que podem ir desde $\mathrm{R} \$ 218,00$ a $\mathrm{R} \$ 287,00$, de acordo com as marcas, todavia, todas fabricações nacionais. Destaca-se que foi identificada nas embalagens das tintas utilizadas pelos respondentes, mensagens de que tal produto era prejudicial à vida marinha.

Quando os respondentes foram questionados sobre o conhecimento dos efeitos do uso dessas tintas na natureza, foram unânimes em afirmar que desconhecem qualquer reação direta dessas influências. Contudo, dentre as informações apuradas em relação às tintas, os entrevistados indicaram não conhecer outro produto que seja capaz de minimizar os ataques contínuos das espécies grudentas, bem como, foi citado que o uso dessas tintas para embarcações é parte da história deles há muitos anos, haja vista que alguns entrevistados disseram que desde a época de seus avós, o método de proteção dos cascos das embarcações ocorre mediante o uso desse tipo de material. 


\section{CONCLUSÃO}

A problemática do microlixo é mundial e está gerando impactos ambientais na biodiversidade de diferentes ecossistemas. A constatação de que as embarcações marítimas são todas elas cobertas pelas tintas venenosas que deixam resíduos de plástico tóxico no ambiente, indicam a necessidade de novas pesquisas que visem desenvolver tintas anti-incrustantes para os cascos de embarcações que não contribuam para a poluição marinha.

Nesse mesmo contexto, é preciso destacar também que apesar da legislação indicar a proibição do uso de tintas venenosas desde 2008, e com base no relatado pelos donos e marinheiros das embarcações, é possível constatar que a tinta continua sendo utilizada, haja vista não existir no mercado nenhum produto que seja capaz de suprir a necessidade dessas populações na manutenção de embarcações de madeira. 


\section{REFERÊNCIAS BIBLIOGRÁFICAS \\ REFERENCIAS BIBLIOGRÁTICAS}

1. Falcão PM; Souza CRG (2011). Avaliação do conhecimento sobre a presença de grânulos plásticos (pellets) em áreas litorâneas do mundo: 1970-2011. XIII Congresso da Associação Brasileira de Estudos do Quaternário ABEQUA.

2. Manzano, A.B. Distribuição, taxa de entrada, composição química e identificação de fontes de grânulos plásticos na Enseada de Santos, SP, Brasil. Dissertação. São Paulo: Instituto Oceanográfico / USP, 2009.

3. Godoi AFL; Favoreto R; Silva MS (2003). Contaminação ambiental por compostos organoestânicos. Quim. Nova, Vol. 26, No. 5, 708-716, 2003.

4. Martins TL; Vargas VMF. Riscos à biota aquática pelo uso de tintas anti-incrustantes nos cascos de embarcações. Ecotoxicol. Environ. Contam. v. 8, n. 1, 2013, 01-11.

5. Pedruzzi FC; Tagliani PRA. Diagnóstico do uso e controle de tintas antifouling no Brasil. IV Congresso Brasileiro de Gestão Ambiental Salvador/BA - 25 a 28/11/2013. 